\title{
INSAR COLLABORATIVE MONITORING MODE AND MULTI-MODE COMPUTING SERVICES FOR GEOHAZARDS IDENTIFICATION IN OPEN-PIT MINING AREA
}

\author{
ZHANG Jin ${ }^{1}$ \\ ${ }^{1}$ Taiyuan University of Technology, 030024, Taiyuan, China, zhangjin@tyut.edu.cn
}

KEY WORDS: InSAR, Geosensor Network, Collaborative Monitoring mode, geohazards, Open-pit mine,

\begin{abstract}
:
InSAR has developed a variety of methods, such as D-InSAR, PS-InSAR, MBAS, CT, SqueeSAR, POT, etc., which have been widely used in land subsidence monitoring. For open pit mining areas, there are usually mining activity, complex terrain features, low coherence, and local large deformation gradients, which makes it difficult for time series InSAR technology to obtain high-density surface deformation information in open pit mining areas. Traditional methods usually only monitor the linear deformation of the surface caused by the mining of a few working zone above the underground mining area, and the temporal and spatial resolution is lower. How to obtain high-precision, high-density, and time-sensitive deformation information is the main difficulty of InSAR monitoring in open pit mining areas. Make full use of the geosensor network monitoring system , optimize monitoring mode of collaborated satellite-to-ground based InSAR, further realize whole calculation and geographic information services, to achieve early identification and discovery of abnormal in large-area macro-monitoring, and accurate monitoring of local areas in real-time early warning, which is the development direction of ground deformation monitoring of mining areas. The study area is Pingshuo open pit mining area. we fully study the application mode and services of InSAR monitoring for geohazards in open-pit mining area, through the establishment of satellite InSAR technology system for large-scale macro-monitoring and forecasting, and GBSAR and GSN for local precision monitoring. The effective mode of InSAR monitoring of geohazard in open-pit mines is summarized. A combination of D-InSAR, POT (Pixel offset tracking), Time Series-InSAR and GB-SAR is used in a wide range, and high-resolution optical images are used to identify localized changes in subsidence areas and open-pit mining areas.
\end{abstract}

\section{INTRODUCTION}

InSAR has developed a variety of methods, such as D-InSAR, PS-InSAR[Alessandro Ferretti, Claudio Prati, and Fabio Rocca, 2001 and Hooper Andy, Segall P, Zebker H.A., 2007], MBAS[Francesco Casu, Mariarosaria Manzo, Antonio Pepe, and Riccardo Lanari, 2008], CT[Oscar Mora, Jordi J. Mallorqui, and Antoni Broquetas,2003], SqueeSAR, POT[Bingqian Chen, Zhenhong Li, Chen Yu, David Fairbairn, et al, 2020], etc., which have been widely used in land subsidence monitoring. Due to the interference of time decorrelation, geometric decorrelation and atmospheric effects, time series InSAR technology based on stable point targets has gradually replaced traditional DInSAR technology as a new method for high-precision monitoring of land surface subsidence. The PS points with stable phase information are selected from multiple SAR images. Under the influence of atmospheric delay, these PS points can maintain good coherence even if the surrounding geographical features and terrain are seriously decoherent. By analysing the phase information of the PS point, the deformation rate, atmospheric delay correction amount, and DEM error are calculated and obtained.

At present, the application of time series InSAR surface subsidence monitoring technology is mainly concentrated in urban areas. For mining areas, there are usually more vegetation coverage, low coherence, and large deformation gradient, which makes it difficult for time series InSAR technology to obtain high-density mining area surface deformation information. In fact, it is difficult for traditional linear deformation observation to fully reflect the temporal and spatial evolution of the threedimensional deformation of the whole mining area. How to obtain high-precision and high-density deformation information is the main difficulty of InSAR monitoring in mining area, especially for open pit mine. 
Combining GNSS and InSAR technology to measure ground deformation in the mining area, obtain ground subsidence information caused by coal mining [Dong Jiang, Jin Zhang, Zikuan Zhou, et al, 2010], and use GIS technology to comprehensively analyze the ground subsidence process and coal mining process [Francioni M, Salvini R, Stead D, et al, 2015]. it also can get the ground subsidence changes information synchronized with the coal mining process.

Combine high-resolution SAR images and high-resolution optical images to determine the location, size, boundary and other characteristics of the ground disaster feature objects in the mining area, and establish a typical mining area ground disaster catalogue map realized by applying SAR technology.

The collaborative monitoring of the geosensor network (GSN) and optical remote sensing are studied, as well as the fusion calculation method where GSN and the satellite remote sensing observation results are mutually additional information or constraint conditions, build a comprehensive monitoring system of point, line and surface integration of geohazards in mining areas[Zhang Jin, 2016]. Research is focus the collaborative monitoring modes and computing services for large area and local area and important area how to use TS-InSAR, DInSAR, POT and GBSAR and high-resolution satellite imagery and GSN technology for geohazards identification in open-pit mine.

\section{COLLABORATIVE MONITORING MODE}

The collaborative monitoring mode is how to combine multiple vertical observations such as Geosensor Network, InSAR, LiDAR, and inversion techniques where multiple remote sensing observation results are mutually additional information or constraint conditions, and build to the point, line and surface integrated monitoring methods for the geohazards of open-pit joint mining area. From point-line collaboration, point-surface collaboration, and surface-surface collaboration, a satelliteground collaboration data fusion calculation system is constructed, and GNSS, georobots, ground laser scanning and satellite remote sensing data can be used to achieve loose combination and tight combination level fusion calculations. See figure 1 .

Cooperate with InSAR surface deformation monitoring, GBSAR ground high dynamic area and GSN precision monitoring technology to build a satellite-ground collaborative monitoring service model. In low-coherence areas, by fusing the monitoring data of GSN to improve the observation density and resolution accuracy of InSAR, and realize the fine acquisition of line-ofsight deformation information of the mining area.

The study area is Pingshuo mining area. The mining methods of the Pingshuo mining area include open-pit and underground mining. It is located the northern part of Shanxi Province, China. The main mining area covers about $400 \mathrm{~km}^{2}$. The deformationrelated areas include mining area, dumps, industrial squares, railway lines, power supply towers, etc. The disasters involved include cracks, subsidence, collapse, landslides, etc. The range of deformation is large and the situation is complicated. At present, the company only conducts manual inspection in large area, automatic monitor based on GSN consisting of georobots, GNSS and GB-SAR (Ground Based SAR) and analyzes in local and special area for slope and special slope areas and the dump site, which cannot cover the entire area due to coal mining.

So we fully study the application mode and services of InSAR monitoring for geohazards in open-pit mining area, through the establishment of satellite InSAR technology system for largescale macro-monitoring and forecasting, and GBSAR and GSN for local precision monitoring. The effective mode of InSAR monitoring of geohazard in open-pit mines is summarized. A combination of D-InSAR, POT (Pixel offset tracking), TSInSAR and GB-SAR is used in a wide range, and high-resolution optical images are used to identify localized changes in subsidence areas and open-pit mining areas.

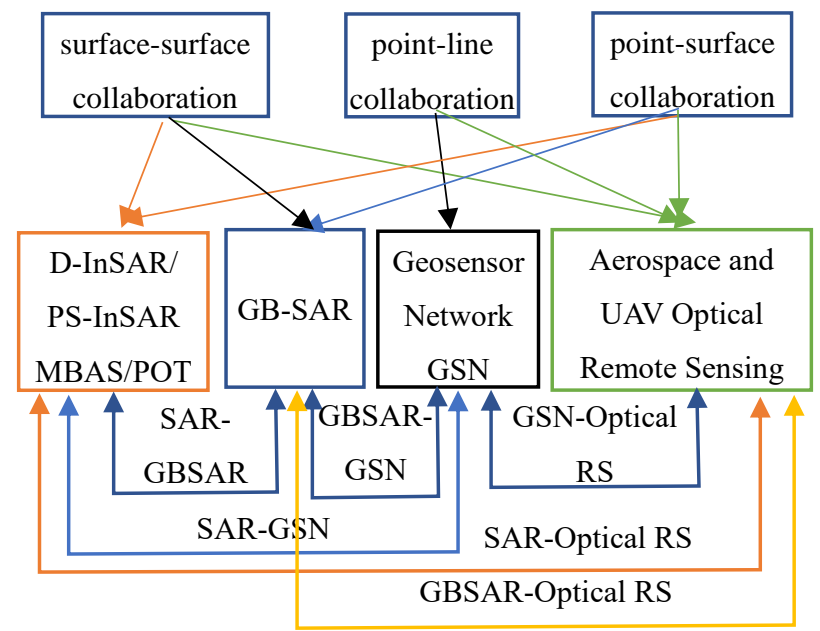

Figure 1. Collaborative Monitoring Mode

The method of POT is used to monitor large gradient subsidence or surface change, four-steps strategy to complete offset tracking are concluded. The area with obvious local time-varying features uses ground-based SAR to monitor real-time changes. The special disaster-hazard areas use the integrated monitoring mode of GSN monitoring system 
Time series InSAR and SBAS technology based on StaMPS are used, which compute of high-resolution SAR data for surface deformation monitoring in Pingshuo mining area. Establish a operation process and an early identification knowledge database for abnormal data and real danger, and use GIS technology to provide early warning services for ground disaster monitoring.

\subsection{Collaborating InSAR with GSN Monitoring System}

Collaborating satellite InSAR of large-extends surface subsidence monitoring with geosensor network monitoring system, such as ground-based SAR of high dynamic local area monitoring and GNSS precise monitoring of specific surface feature points, satellite-ground collaborative monitoring are constructed and the effectiveness of monitoring are evaluated.

\subsection{Collaborating GSN with Optical Remote Sensing}

Collaborating geosensor network with optical remote sensing, and the fusing computation of the observation results, additional information, or constraints relationship between the geosensor network and satellite remote sensing, the integrated monitoring and analysing system is built for mining geohazards monitoring. By fusing high-resolution SAR image and high-resolution optical image, the location, size, boundary and other characteristics of the mining area geohazards feature object are determined, and the typical mining area geohazards inventory map is established.

\subsection{Constraint Computing of Collaborating Monitoring}

The Constraint computing of collaborating monitoring is the important theory and method to realize the geosensor networks collaborative monitoring and application. Taking the horizontal deformation rate calculated by the geosensor network as a constraint, the slant range deformation rate obtained by InSAR is decomposed into vertical deformation rate and horizontal deformation rate enhanced by the joint computing of satelliteground collaborative monitoring.

\section{COLLABORATIVE MONITORING METHOD}

\subsection{PS-DInSAR Monitoring Methods for Mine Subsidence}

The high-resolution SAR data of surface deformation monitoring in Pingshuo mining area were processed and analyzed by DInSAR and time series InSAR data respectively, and the displacement and subsidence maps of the monitored area were obtained. The processing results of the COSMO data and the GPS measured data were compared and analyzed. The method and approach to improve the accuracy of image registration and the efficiency of phase unwrapping are studied, and the influence of parameter selection in the data processing process and result is analyzed. See figure 2 and figure 3.
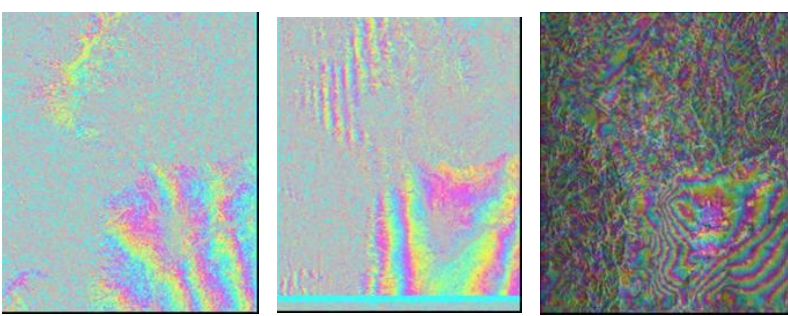

Figure 2. Displacement Map

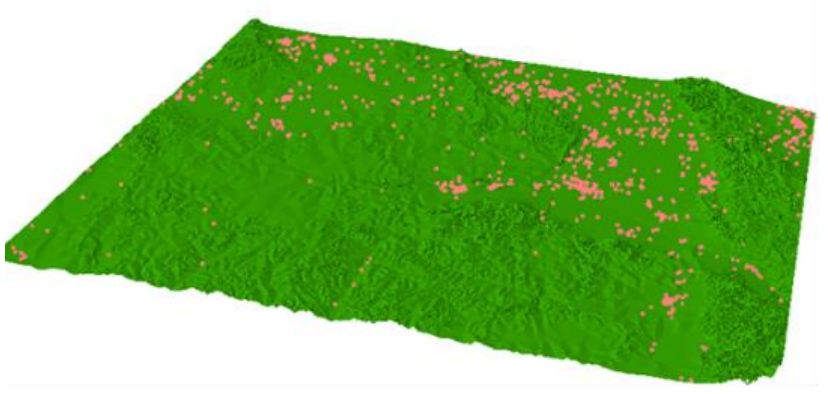

Figure 3. PS points 3D distribution

\subsection{SBAS-InSAR Subsidence Monitoring in Mining Area}

The small baseline subset radar interferometric technology improves the monitoring capability of InSAR technology in areas with low coherence such as suburbs or mining areas by optimizing the combination of interference pairs. Based on StaMPS, use Sentinel-1A/B data to analyze the time series of surface subsidence in open-pit mine. Firstly, analyze the time series displacement of LOS and the annual average displacement velocity; secondly, select some scatterer points in the open-pit stripping, mining and dump zone to analyze the displacement trend of different time periods in the local area. Dump zone has more obvious vertical displacement than horizontal displacement. There are large gradient deformations and engineering topographical changes in the mining and stripping zone, resulted serious phase decorrelation. Finally, the cumulative displacement of vertical and horizontal directions in the whole open pit mining area are calculated. See figure 4 . 


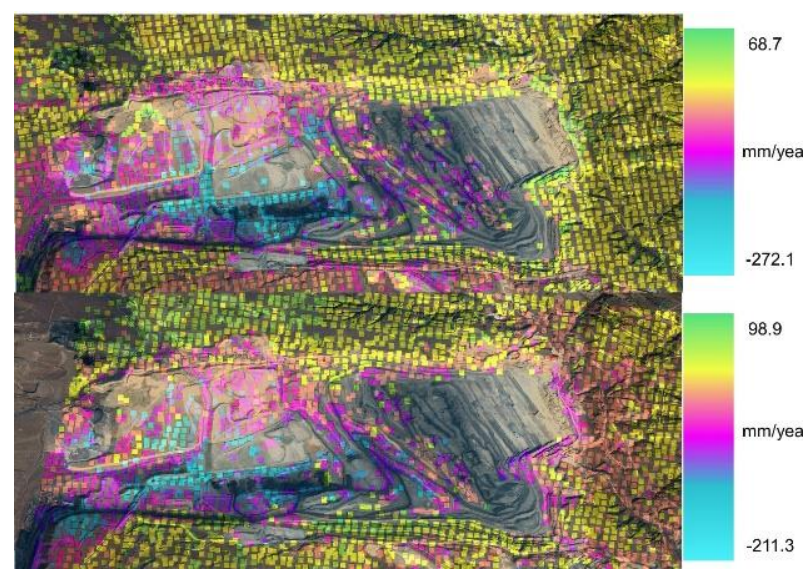

Figure4. Annual average LOS displacement velocity

\subsection{Big Gradient Deformation Based on Calculating Offsets from SAR Images}

The topography of open-pit mines is complex and the correlation of different areas varies with coal mining. Intensity-based SAR offsets tracking method determines the best matching position according to the principle of Normalized Cross Correlation (NCC) and used to calculate big subsidence of open-pit mine. For regions with low correlation, the topographic changes are identified by analyzing the texture features of images in the matching window. Two scene Sentinel-1A SLC images were used to analyze subsidence and topographic changes. Assisted textures can detect the topographic change area. See figure 5 and figure 6 .
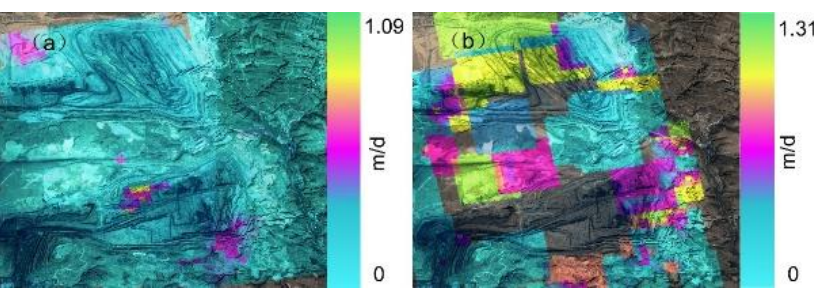

Figure 5. Offsets velocity distribution in the study area

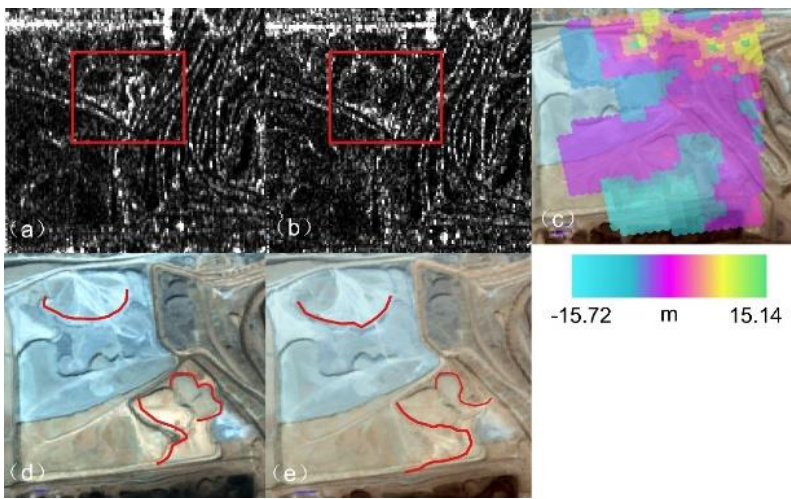

Figure 6. Topographic changes and displacement of the dump

\subsection{GB-SAR Geohazards Monitoring}

Ground-based Interferometric Radar (GB-SAR) is a significant technique to monitor the deformation of open-pit mine side slope It has high sensitivity to small deformations, in the region of submillimeter to millimeters, which is achieved by exploiting the interferometric capability of centimeter-wavelength microwaves. It is a long-range measurement device, which can work up to some kilometers. It can provide, in an automatic way, massive deformation measurements. In particular, the GB-SAR technique can be used to monitor a wide range of deformation phenomena, ranging from a few millimeters per year up to meters per day.

Monitoring efficiency analysis provides the basis for optimization selection of the observation station. First, basic conditions of selection of the GB-SAR observation station are discussed, then analyzed the internal and external factors that impact GB-SAR monitoring efficiency. Finally, considered the influences factors of landform and surface. the GB-SAR monitoring process data, result data and categorical data be used, visualization integrating remote sensing image and DEM together to GB-SAR deformation monitoring data enhances the presentation effects of GB-SAR. It can visualize monitoring area's deformation information more intuitively and clearly. See figure 7.

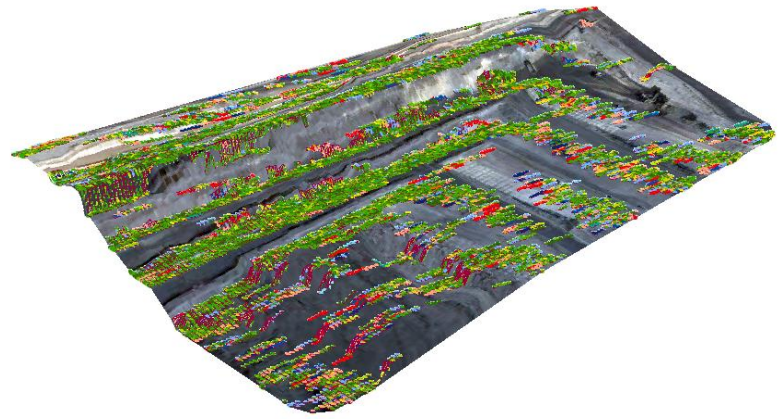

Figure 7. 3D visualization deformation monitoring effect after data fusion

\subsection{GSN Geohazards Monitoring System}

GIS-based sensor network and real-time GIS are becoming one of the research hotspots in the field of Geomatics. A deep investigation into the theory of collaborative computing of geosensor network would play a significant role in forming a technical service system for monitoring and early warning of geohazards in mine areas. Such a system in turn holds great values for both scientific research and practical application once 
it could provide, in time, an accurate and reliable forecast of the geohazard and give guidance on minimizing the losses.

Geosensor networks is mainly referred to the sensor networks which is based on the GPS, Georobot, terrestrial 3D laser scanner and ground SAR and other geodetic type sensors, and other related sensors about tilt, displacement, temperature, pressure, rainfall, images and so on, in addition, which also be constructed by the application of computer network and wireless communication technology, sensors and database management system. See figure 8 .

Make full use of GSN monitoring system to realize early identification and discovery of problems in large-scale macro monitoring, and accurate monitoring of local areas in real-time warning. Application self correlation coefficient, Q statistic on the monitoring data of stochastic, stability, periodicity, and trend recognition, using variation function of spatial data in some scattered data points sensitive characteristics, definition the influence curve under disturbance model, disturbances including ground geo-environment, the underground geo-environment disturbance, using the influence coefficient method and estimate neighborhood method to identify the spatial information of abnormal point, identification of disaster events. See Figure 9.

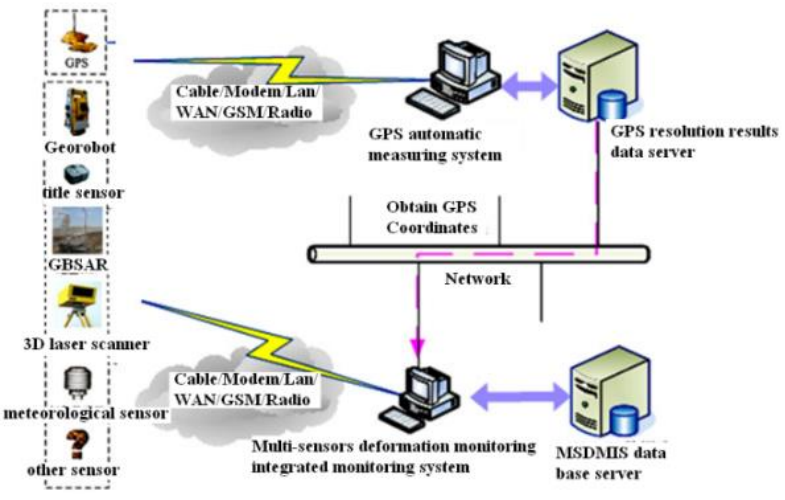

Figure 8. Geosensor Network

\section{MULTI-MODE COMPUTING AND SERVICES}

4.1 The geo-environment characteristic Associated with disaster and spatial variation

Geosensor network collaborative monitoring fusion calculation, spatial variability and temporal-spatio evolution mechanism is the most of important scientific problem. Based on the three aspects of the basic factors, development factors and Inducing factors, the data set of the geo-environment characteristic factors of the mine disaster area is established. Based on regional high precision digital elevation model data, mine surveying data, regional surface coverage data and historical meteorological data and underground rock soil detection results of calculation and analysis, extraction mining area elevation, slope, slope type, gully density and water influence from the characteristic factor.

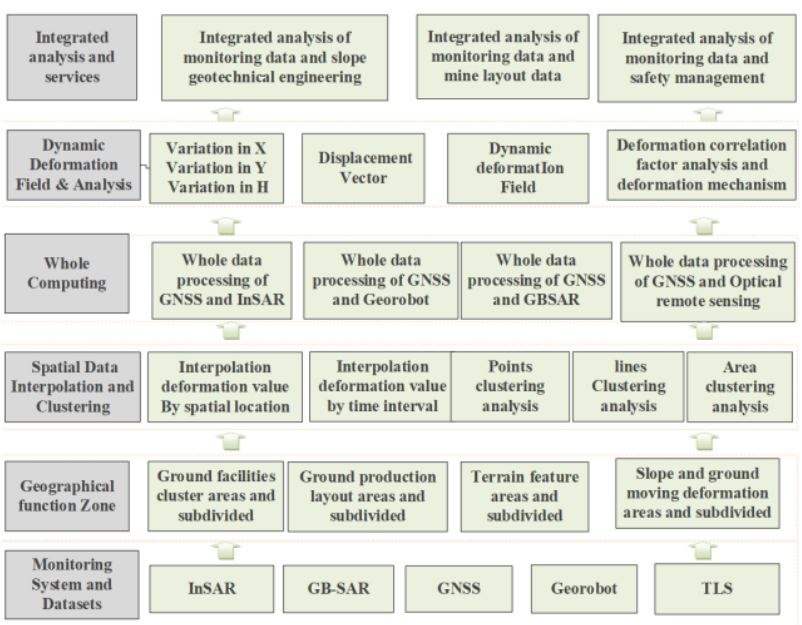

Figure 9. Computing Theory Framework of Geosensor Network

The early identification knowledge database for abnormal data and real danger are established, and early warning services for ground disaster monitoring are implemented based on GIS services.

\subsection{Geographical Information Service of Geohazards Monitoring}

Based on OGC sensor information model and standards, the development of the Geosensor information model, realize the mutil-geosensor real-time access. Based on unified temporal and spatial datum, used multi-geosensor data fusion processing method, realize the time sequence data of the geosensor integration calculation. discovered abnormal monitoring information, and early warning system deployed and released.

All monitoring data is storied into MongoDB database. We develop the data analysis software of MDA_GIS, the monitoring point, line and area feature can be analyzed and visualized real time in MDA GIS. The horizontal and vertical movement is represented by dynamic deformation field in a certain time interval which helps to analyse the deformation mechanism, process, early warning and forecasting.

An geo-infographic map is defined as a visualization of data or ideas that tries to convey complex information to an audience in a manner that can be quickly and easily understood, which is helpful to convey specific information. The knowledge and geoinfographics map are used to obtain the better application effect 
in the data and information visual representation of the GSN, see Figure 10 .

Extract structured event knowledge from geo-infographics map, and mine the characteristics of the event in the time dimension, succession or dependency dimension. From the aspects of data features, concept description, classification, clustering, correlation analysis, association modeling, change and deviation analysis, etc., establish a semantic classification system for geoinfographics map, and associate knowledge discovery methods and sequential pattern knowledge discovery methods, etc., carry out semantic classification and analysis of multi-field geoinfographics map, and realize the standardized description, semantic structure, formalization, spatial expression and temporal-spatial relationship analysis of geohazards geoinfographics map.

The dashboard methodology of GSN represents monitoring point change information, using the calendar panel represents changes with the date of GSN data, using the block area thematic map represents early warning information. Event driven disaster warning service chain construction and early warning visualization services are main contents of geosensor network service.

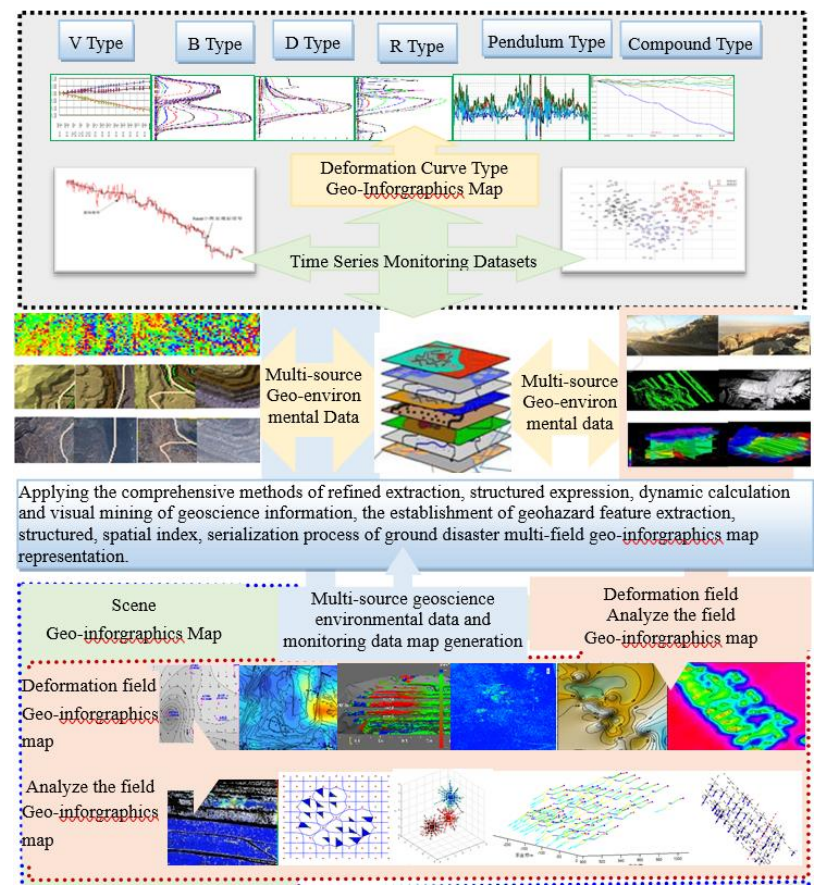

Figure 10. Types, shapes and data relationships of

Geo-inforgraphics Map of Geohazards in mining areas

\section{CONCLUSIONS}

The time series InSAR surface subsidence monitoring technology, for mining areas, are usually mining activity, complex terrain features, low coherence, and local large deformation gradient, which makes it difficult for time series InSAR technology to obtain high-density mining area surface deformation information. Research is focus the collaborative monitoring modes and computing services for large area and local area and important area how to use TS-InSAR, DInSAR, POT and GBSAR and high-resolution satellite imagery and GSN technology for geohazards identification in open-pit mine.

Combining GNSS and InSAR technology to measure ground deformation in the mining area, obtain ground subsidence information caused by coal mining and use GIS technology to comprehensively analyze the ground subsidence process and get the ground subsidence changes information synchronized with the coal mining process.

Combine high-resolution SAR images and high-resolution optical images to determine the location, size, boundary and other characteristics of the ground disaster feature objects in the mining area, and establish a typical mining area ground disaster catalogue map realized by applying SAR technology.

The application mode and services of InSAR monitoring for geohazards in open-pit mining area are introduced. The effective mode of InSAR monitoring of geohazard in open-pit mines is summarized, that is satellite InSAR technology system for largescale macro-monitoring and forecasting, and GBSAR and GSN for local precision monitoring. A combination of D-InSAR, POT, Time Series-InSAR and GB-SAR is used in a wide range, and high-resolution optical images are used to identify localized changes in subsidence areas and open-pit mining areas.

\section{ACKNOWLEDGEMENTS}

This work was supported by the National Key Research and Development Program (No. 2018YFB0505402) and funded by the Natural Science Foundation of China(No. 41771443).

Guo Jiaojiao, Du Sunwen and Sun Jun participated in part of the research work.

Author thanks to the Sentinel-1A/B image data provided and SNAP open source InSAR software developed by ESA, and also to StaMP open source InSAR software developed by Andy Hooper. 


\section{REFERENCE}

Alessandro Ferretti, Claudio Prati, and Fabio Rocca, 2001. Permanent scatterers in SAR Interferometry, IEEE Transactions on Geoscience and Remote Sensing, 39(1):8-20.

Bingqian Chen, Zhenhong Li, Chen Yu, David Fairbairn, et al, 2020.Three-Dimensional Time-Varying Large Surface Displacements In Coal Exploiting Areas Revealed Through Integration Of Sar Pixel Offset Measurements And Mining Subsidence Model, Remote Sensing of Environment, 240(111663), 1-12

Dong Jiang, Jin Zhang, Zikuan Zhou, et al, 2010. Analysis of Ground Subsidence in Coal Mining Area Using High Resolution SAR Data, International Workshop Spatial Information Technologies for Monitoring the Deformation of Large-Scale Man-made Linear Features, The Chinese University of Hong Kong, China, 11-12.

Francesco Casu, Mariarosaria Manzo, Antonio Pepe, and Riccardo Lanari, 2008. SBAS-DInSAR Analysis of Very Extended Areas: First results on a $60000-\mathrm{km} 2$ test site, IEEE Geoscience and Remote Sensing Letters, 5(3): 438-442.

Francioni M, Salvini R, Stead D, et al, 2015. An Integrated Remote Sensing-GIS Approach for the Analysis of an Open Pit in the Carrara marble District, Italy: Slope stability assessment through kinematic and numerical methods, Computers and Geotechnics, 67:46-63.

Hooper Andy, Segall P, Zebker H.A., 2007. Persistent scatterer InSAR for Crustal Deformation Analysis with Application to Volcán Alcedo, Galápagos, Journal of Geophysical Research, 112( B07407):1-21.

Oscar Mora, Jordi J. Mallorqui, and Antoni Broquetas, 2003, Linear and Nonlinear Terrain Deformation Maps From a Reduced Set of Interferometric SAR Images,IEEE Transactions on Geoscience and Remote Sensing, 41(10):2243-2253

Zhang Jin, 2016. Geosensor Networks and its Application in Coal Mine Ground Disaster Precision Monitoring, XVI International Congress for Mine Surveying, Brisbane, Australia, 12-16. 